\title{
Isolation, characterization and primary screening of soil actinomycetes from Kenyatta University arboretum grounds for antibacterial activities
}

\author{
Osborn Yamakhakha Khasabuli and Anthony Nyamache Kibera \\ Kenyatta University (main campus), P.O. Box 43844, Nairobi, Telephone: Tel: +254 20 8710901, +254 208711622 , \\ Fax: +254 20 8711575, Website: www.ku.ac.ke . Email: info@ku.ac.ke. \\ Khasabuli10@gmail.com and akibera2000@gmail.com
}

Original submitted in on $9^{\text {th }}$ November 2012 Published online at www.m.elewa.org on $28^{\text {th }}$ February 2014. http://dx.doi.org/10.4314/jab.v74i1.12

\begin{abstract}
Objective : Antimicrobial resistance has increased drastically in recent years in the developing countries, and it has leading public health concern. With almost all organisms becoming multidrug resistant to the commonly used antibiotics, there is a need to search for more drugs that are novel in order to address this challenge. Therefore, this study was aimed at isolating antimicrobial producing actinomyscetes and to evaluate their secondary metabolites against selected multidrug resistant bacteria isolates.

Methodology: Half kg soil samples were collected $15 \mathrm{~cm}$ below the ground. Starch Casein Agar (SCA) was used to isolate actinomycetes. Fifteen different actinomycetes identified as Is.1-Is.15 were isolated. They were differentiated based on the difference in appearance of the colony morphology and mycelial structure. Their metabolites were tested for antibiotic activities through the primary screening using the disk diffusion methods. Test bacteria were; Bacillus subtilis, E.coli, Klebsiella Pneumoniae, Staphylococcus aureus, Shigella sonei and Salmonella typhi. All the secondary metabolites from the isolated actinomycetes proved to posses the ability to inhibit bacterial growth by formation of different sized halo zones.

Conclusion and application: Secondary metabolites produced by actinomycetes have the ability to inhibit growth of pathogenic bacteria. The ability of these metabolites to inhibit growth of test pathogenic bacteria has been attributed to the establishment of the fact that novel antibiotics can be manufactured from metabolites produced by actinomycetes. Large scale manufacture can be done through purification of these metabolites to ensure large scale production of novel drugs. This can serve help clear pathogenic bacteria that are ever developing resistance on the available antibiotics.
\end{abstract}

Key words: Actinomycetes, metabolites, soil, antimicrobial activity

\section{INTRODUCTION}

Actinomycetes are a group of organisms originally considered to be intermediates between fungi and bacteria. The study of Cummins and Harris (1956) established that actinomycetes have a cell wall composition resembling that of Gram positive bacteria. They are also branching unicellular microorganisms. They produce mycelium which may either be aerial or may spread on the substrate on which the microorganism is growing (Harvey, 2007). The mycelia in some species may break to form rodor coccoid-shaped forms. Many genera also form spores; the sporangia or spore cases may be found 

arboretum for antibacterial activities.

on aerial hyphae, on the colony surface or free within the environment. They posses DNA that contains high amounts of Guanine + Cytosine ( $>55 \%)$ (Cummins and Harris, 1956) Among these groups of microorganisms, streptomyces are dominant. The others referred to as the non-actinomycetes are called the rare actinomycetes. The majority of the actinomycetes are free living (Ceylan, Okmen and Ugur, 2008). Actinomycetes are one of the major constituents of soil microorganisms, together with some bacteria as well as some fungi. Some inhabit marine environments while others groups live in mangrove environments (Kumar, 2001). They play an important role in decomposition of organic materials such as cellulose and chitin and thereby playing a vital part in organic matter turnover and carbon cycle (Williams et al., 1971). Actinomycetes are known to produce diverse metabolites from their complex biochemical processes. Over 23,000 microbial secondary metabolites are known including the betalactam antibiotics like penicillin and cephalosporins and some form the shikimic acid like chloramphenicol for example (Barrios-Gonzalez et al., 2003). Approximately, $42 \%$ of these metabolites are known to be produced by actinomycetes, $16 \%$ by fungi and other bacteria. Among various genera, Streptomyces, Saccharopolyspora, Amycolatopsis,

\section{METHODOLOGY}

Study site and sample collection: The soil samples were collected from virgin arboretum grounds of Kenyatta University. This enabled evaluation of a group of antibiotic producing actinomycetes that were inhabitants of that region. Half kilograms of soil samples were collected about $10 \mathrm{~cm}$ below the ground surface and packed in polythene bags and carried to the Kenyatta University convectional laboratories (BZ6PMS) for analysis. The collected samples had labels identifying the field, sample and date of collection. The fields were labeled 1, 2 and 3 . Sample from field 1 had labels $1 a$ and $1 b$, field 2 had labels $2 a$ and $2 b$ finally field 3 had labels $3 a$ and $3 b$. The digits 1, 2 and 3 were the codes representing the areas from where the samples were collected. The samples were air dried over the benches for one week. This was done to help reduce the population of Gram negative bacteria (Jeffrey et al., 2008).

Microbe isolation: The soil suspension technique described by Oskay et al., (2004) was used. One gram of
Micromonospora and Actinoplanes are the major producers of commercially important biomolecules. These metabolites are released into the environment. They have broad spectrum biological activities such as antibacterial, antifungal, antiviral, antiparasitic, immunosuppressive, antitumor, insecticidal, anti-inflammatory, antioxidant, enzyme inhibitory and diabetogenic (Sacramenti et al., 2004). Those that produce antibacterial and antifungal metabolites may pose several effects on the immediate surrounding and the major one is that of inhibiting other microorganisms from growing or multiplying. These groups of actinomycetes are referred to as the biological antagonistic types. They are of special interest since they are the ones that are exploited and their metabolites used in the manufacture of antibiotics. Microbial metabolites are a source of life saving environments for bacterial and fungal infections. This is because they are used in the manufacture of some of the effective antibiotics including: penicillin, erythromycin, streptomycin, tetracyclines, vancomycin and amphotericin. These microbial natural products are notable not only for their potent therapeutic activities but also for the fact that they frequently pose desirable pharmacokinetic properties required for clinical development (Kekuda et al., 2010).

the soil sample was measured and mixed with $9 \mathrm{ml}$ of sterile distilled water $\left(\mathrm{sdH}_{2} \mathrm{O}\right)$. The soil suspension was shaken vigorously under room temperature $\left(25 \pm 2^{\circ} \mathrm{C}\right)$ on an orbital shaker at $200 \mathrm{rpm}$ for $10 \mathrm{~min}$. $100 \mu \mathrm{l}$ of the soil suspension was pipetted and lawn onto Starch Casein Agar (SCA) (Soluble starch, $10.0 \mathrm{~g}$; Casein hydrolysate, $0.3 \mathrm{~g} ; \mathrm{KNO}_{3}, 2.0 \mathrm{~g} \mathrm{NaCl}, 2.0 \mathrm{~g} ; \mathrm{K}_{2} \mathrm{HPO}_{4}, 2.0 \mathrm{~g}$; $\mathrm{MgSO}_{4} .7 \mathrm{H}_{2} \mathrm{O}, 0.05 \mathrm{~g} ; \mathrm{FeSO}_{4} .7 \mathrm{H}_{2} \mathrm{O}, 0.01 \mathrm{~g} ;$ Agar, $18.0 \mathrm{~g}$; distilled water, $1000 \mathrm{ml}$ (Jeffrey, 2008). The plates were done in duplicates. One set was incubated at room temperature while the other set incubated at $37^{\circ} \mathrm{C}$. At $37^{\circ} \mathrm{C}$ colonies were fully grown after 24 hours while at $25^{\circ} \mathrm{C}$ colonies grew fully after 7-10 days. Incubation at $37^{\circ} \mathrm{C}$ was efficient since the temperature was favorable for faster growth of actinomycete as well as serve optimum temperature for bacterial growth.

Identification and characterization: A total of 15 isolates were obtained and identified as Is.1, Is.2, Is. 3 ... and Is. 15 based on their differences in colony morphology 


\section{Khasabuli and Kibera. J. Appl. Biosci. 2014. Screening of soil actinomycetes from Kenyatta university}

arboretum for antibacterial activities.

(Table 1). Preliminary identification of the colonies was done based on morphological observations both microscopic and macroscopic. Microscopically, filamentous colonies were sub cultured on fresh nutrient agar and incubated at $37^{\circ} \mathrm{C}$ to obtain pure cultures.

Microscopic observations: A simple stain technique using methylene blue was used. A mass of colony was scooped using a wire loop, spread on a clean slide, air dried and fixed by passing over a flame twice. The slide was then flooded with methylene blue stain and after 3 seconds the excess stain washed off in running tap water. The slide was then blot dried and observed using a light microscope with $\times 40$ magnification objective (Photograph1, pg13). This was a preliminary identification technique for the actinomycetes.

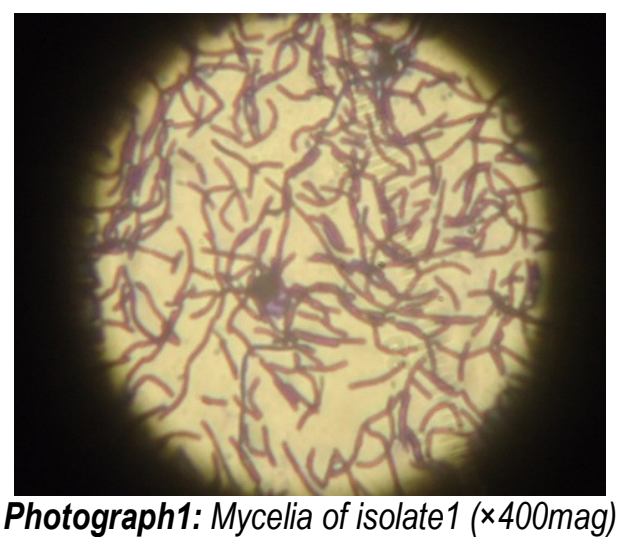

Macroscopic observations: This included observing the morphological characteristics of the colonies. Table1 gives the details of the observations.

Pure cultures: The cultures were ascertained as pure only when the culture plate had only one group of the organism growing (Michael et al., 2009). Broth cultures were then prepared by inoculating the pure cultures in nutrient agar broth and incubating at $37^{\circ} \mathrm{C}$ for one week. These cultures were sealed with parafilm and kept undisturbed in the fridge for subsequent analysis (Plate 2). Also the culture plates were at all times sealed using the parafilm to avoid mites from invading the plates.

Table1: Colony characteristics.

\begin{tabular}{|l|l|}
\hline Isolate & Colony characterization. \\
\hline Is.1 & $\begin{array}{l}\text { Irregular, moist, undulate margin, glistening surface, translucent, crateriform elevation. Colony size ranged from } \\
\text { 2mm-4mm. }\end{array}$ \\
\hline Is.2 & Irregular in shape with an entire margin, crateriform elevation, opaque, moist and a glistening surface. \\
\hline Is.3 & Irregular in shape, entire margin, flat elevation, moist with a glistening surface, creamish opaque. \\
\hline Is.4 & Irregular, translucent, moist, glistening, lobate with a flat elevation. \\
\hline Is.5 & Moist, opaque, glistening surface, filiform margin, flat elevation with an irregular shape. \\
\hline Is.6 & Irregular, flat, lobate, opaque, glistering, moist. \\
\hline Is.7 & Irregular in shape, moist, translucent, glistening surface, crateriform elevation, lobate margin. \\
\hline Is.8 & Circular in shape, entire margin, crateriform, opaque, moist with a glistening surface. \\
\hline Is.9 & Circular in shape, glistening surface, crateriform elevation, entire margin and moist. \\
\hline Is.10 & Opaque, irregular in shape, moist, lobate margin with crateriform elevation. \\
\hline Is.11 & Irregular in shape with a lobate margin, opaque, raised elevation, whitish in color and appears brittle. \\
\hline Is.12 & Dull colonies, whitish, irregular in shape, moist and umbonate elevation. \\
\hline Is.13 & Translucent irregular colonies, crateriform elevation and moist with a lobate margin. \\
\hline Is.14 & Irregular glistering colonies, crateriform, opaque with a lobate margin and whitish in color. \\
\hline Is.15 & Irregular in shape, opaque and whitish, convex elevation, lobate margin, moist and dull. \\
\hline
\end{tabular}




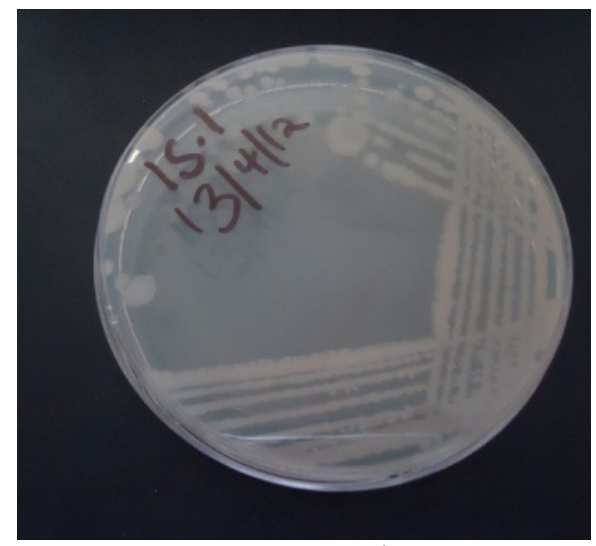

Plate2: Pure isolate1 colonies

Preservation of pure cultures: A sub culture was made but this time the media was Glycerol-arginine agar ( Glycerol $12.5 \mathrm{~g}$, Arginine $1.0 \mathrm{~g}, \mathrm{NaCl} 1.0 \mathrm{~g}, \mathrm{~K}_{2} \mathrm{HPO}_{4} 1.0 \mathrm{~g}$, $\mathrm{MgSO}_{4} .7 \mathrm{H}_{2} \mathrm{O} 0.5 \mathrm{~g}, \mathrm{Fe}_{2}\left(\mathrm{SO}_{4}\right)_{3} .6 \mathrm{H}_{2} \mathrm{O} 0.01 \mathrm{~g}, \mathrm{CuSO}_{4} .5 \mathrm{H}_{2} \mathrm{O}$ $0.001 \mathrm{~g}, \mathrm{ZnSO}_{4} .7 \mathrm{H}_{2} \mathrm{O} 0.001 \mathrm{~g}, \mathrm{MnSO}_{4} \cdot \mathrm{H}_{2} \mathrm{O} 0.001 \mathrm{~g}$, Agar $15 \mathrm{~g}$ and sterile distilled water 1 ltr. The colonies were stored dry at $20^{\circ} \mathrm{C}$. If they were to be required for use again they could be revived by streaking on Starch-

\section{RESULTS}

Halo zones were observed after $24 \mathrm{hrs}$ of incubation while those with resistance, there was significant growth of test organisms (Table 2).

Table2.: Results for sensitivity test.

\begin{tabular}{|l|l|l|l|l|l|l|l|}
\hline Isolates. & Kp & Sf & Ec & Ss & Sa & Bs & St \\
\hline Is. 1 & & - & - & - & - & + & + \\
\hline Is.2 & - & - & - & - & - & + & + \\
\hline Is. 3 & - & - & - & - & - & + & + \\
\hline Is. 4 & - & - & - & - & - & + & - \\
\hline Is.5 & - & + & - & - & - & + & + \\
\hline Is. 6 & + & + & - & - & - & + & + \\
\hline Is. & - & + & - & - & - & - & + \\
\hline Is. 8 & - & - & - & - & + & + & + \\
\hline Is.9 & - & - & + & + & + & + & + \\
\hline Is.10 & - & + & + & + & + & + & + \\
\hline Is.11 & + & - & - & - & + & + & + \\
\hline Is.12 & - & + & - & - & + & - & + \\
\hline Is.13 & - & - & + & + & + & + & + \\
\hline Is.14 & - & + & - & + & + & + & + \\
\hline Is.15 & - & + & - & - & - & + & + \\
\hline
\end{tabular}

Key:

Sf- Streptococcus feacalis

Ec- E.coli

Kp- Klebsiella pnuemoniae

Sa- Staphylococcus aureus

Ss- Shigella sonei
Casein agar and incubated at room temperature for 7 days (Bhagabati et al., 2008).

Antimicrobial activity evaluation: Antimicrobial activity of the secondary metabolites was determined by use of Kirby Bauer disk diffusion method. One week old broth cultures of the actinomycetes were used with sterile paper disks socked in the cultures for 30 minutes were used to inoculate actinomycetes on media seeded with pathogenic bacteria under test at $37^{\circ} \mathrm{C}$ for 24 hours. 
Khasabuli and Kibera. J. Appl. Biosci. 2014. Screening of soil actinomycetes from Kenyatta university arboretum for antibacterial activities.

Analysis: Formation of halo zones (Photograph 3a of Bacillus subtilis) indicated bacterial growth inhibition ability. This showed that the actinomycete produced secondary metabolites that were active against the test bacteria. Absence of halo zone was demonstrated that test bacteria were resistant to the action of the metabolite (Photograph3b. Streptococcus feacalis) (Jeffrey, 2008).

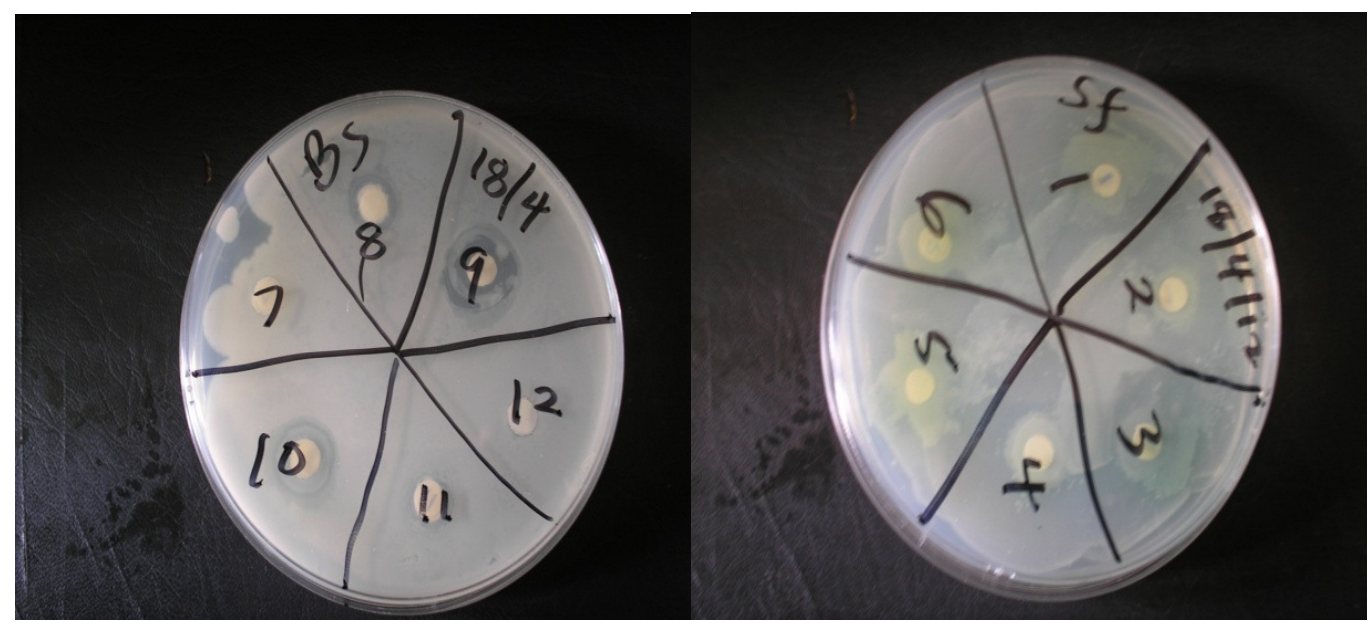

Plate3a. Bacillus subtilis.

Plate3b. Streptococcus feacalis.

Bar graph1 represents graphical presentation of the data.

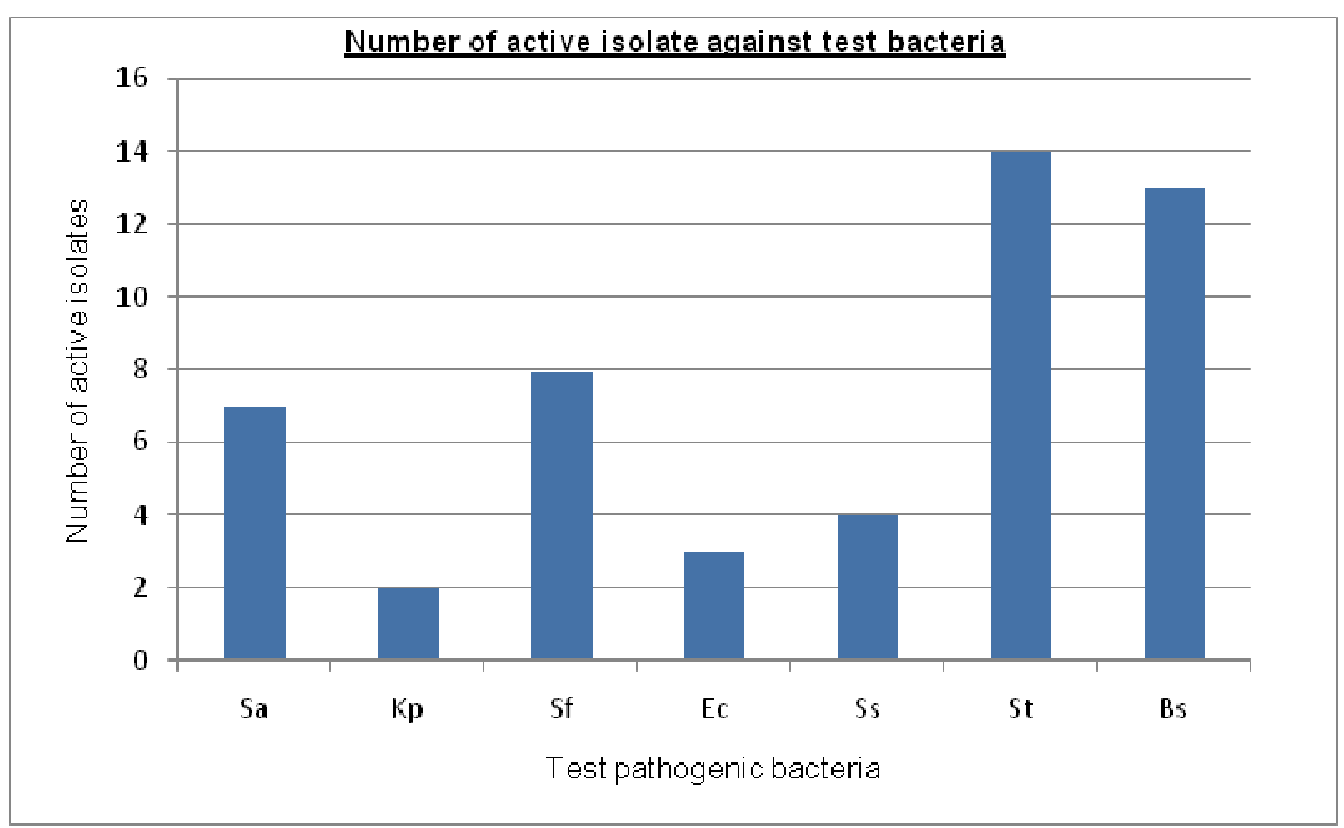

\section{Key:}

Sf- Streptococcus feacalis

Ps- Pseudomonas auregnosa

Ec- E. coli

Bs- Bacillus subtilis

$\mathrm{Kp}$ - Klebsiella pnuemoniae

Sa- Staphylococcus aureus

Ss- Shigella sonei 
Salmonella typhi was susceptible to active metabolites from all the isolates apart from isolate 4. Bacillus subtilis all shown to be susceptible to almost all the isolates apart from isolate 7 and 12. E.coli was resistant to most of the isolates apart from 3 isolates 3, 9, 13 and 14. Shigella sonei was also resistant to most of the isolates apart from

\section{DISCUSSION}

Evaluation for production of active secondary metabolites was done using the disk diffusion method. The $6 \mathrm{~mm}$ disks soaked in the actinomycete broth absorbed the metabolites and carried the actinomycetes' spores as well. The actinomycetes were grown for one week thus enabling them to release their metabolites into the media. The antimicrobial metabolites are known to accumulate under stress conditions like depletion of nutrients (Hopwood, 2000). All the isolates showed positive results. This is because they were able to inhibit growth of some of the test bacteria as was indicated by the formation of a halo zone. Different metabolites from the different isolates acted against the different test bacteria while some metabolites acted against a number of test bacteria. Secondary metabolites from Is.4 were active against $B$. subtilis only while secondary metabolites from Is.1 were active against $B$. subtilis and $S$. typhi. Test bacteria showed varied responses on these metabolites by being susceptible to metabolites from one isolate and resistant to the other isolate. Staphylococcus aureus was susceptible to metabolites from Is.8, 9, 10, 11, 12, 13 and Is.14 while it was resistant to the other metabolites from the remaining isolates. The sizes of the halo zones varied with different metabolites. This was due to differences in the diffusion rates of these metabolites through the agar. These rates of diffusion were dependent on the diffusion and solubility properties of the metabolite. Faster diffusing metabolites formed larger halo zones compared to slow diffusing metabolites (Cheesbrough, 2006). Size of molecular weight of the compounds may also have had effect on the diffusion rates. Compounds with low molecular weights diffused more compared to metabolites with a large molecular weight thus formed lager halo zones (Dougherty and Pucci, 2012). The metabolites are known to diffuse in three dimensions so agar with shallow depths will have the metabolite diffusing more and thus producing large halo zones in contrast to agar with deeper depths. These factors in combination result in each combination having a unique ability in formation of isolate $9,10,13$ and 14 . Isolates $9,10,13$ and 14 proved to be a broader antibiotic spectrum as the acted against most of the isolates. Isolate 7 acted against growth of Salmonella typhi and Klebsiella pneumonia while isolate 4 showed poor activity. It was only active for Bacillus subtilis.

the zone of inhibition indicating susceptibility of the test bacteria to the antimicrobial substance (Jorgensen and Ferraro, 2009 and Wheat, 2001). Point at which critical mass is reached for the compounds is indicated by a sharp margin of the halo zone beyond which no inhibitory activity was evidenced. Resistance among other bacteria may be attributed to several factors among them inoculation of bacterial mass above the critical mass that overpowered the inhibition effects of the metabolites. Bedenic, Beader and Zagar in their studies to determine effect of size of inoculums on antibacterial activity of cefpirome and cefepime against $K$. pneumonia strains known to produce SHV extended-specturm betalactamases established that higher inoculums sizes rendered the strains resistant the two test antibiotics (Bedenic, Beader and Zagar, 2001). There is also the possibility that these bacteria might have acquired the resistant genes from the neighboring resistant bacterial cells in the previous environment (Jorgensen and Ferraro, 2009 and Canton, 2008). The reason for different sensitivity between Gram positive and gram negative bacteria could be ascribed to the morphological differences between these microorganisms, gram negative bacteria having an outer polysaccharide membrane carrying the structural lipopolysaccharide components. This makes the cell wall impermeable to lipophilic solutes (Pandey et al., 2011). The gram positive bacteria would more susceptible due to having only an outer peptidoglycan layer which is not an effective permeability barrier (Davies and Davies, 2010) Susceptibility might also have been contributed by several factors. Synthesis of cellwalls, protein, and membrane of the test bacteria might have been inhibited. There might have been blockage of nucleotide synthesis and membrane function. This resulted to no division and death of bacterial cells. Interpretation of susceptibility or resistance is based on the presence or absence of zones of inhibition surrounding the disks (Jorgensen and Ferraro, 2009). 

arboretum for antibacterial activities.

\section{CONCLUSION}

Research findings from this study show promising results especially for the multi-drug resistant strains. The challenge of drug resistance has become a public health concern and by these findings, it dictates a constant need

\section{ACKNOWLEDGEMENT}

The author wishes to thank all members of staff of Department of Plant and Microbial Sciences Kenyatta University for their support and technical input. Special

\section{REFERENCES}

Barrios-Gonzalez, J., Fernandez, J.F \& Tomasini, A. (2003). Microbial Secondary Metabolites Production and Strain Imporovement. Indian Journal of Biotechnology 2:322-333

Bedenic, B., Beader, N \& Zagar, Z. (2001). Effect of Inoculum Size on the Antibacterial Activity of Cefpirome and Cefepime against Klebsiella pneumonia Strains Producing SHV Extendedspecturm Beta-lactamases. Journal of Clinical Microbiology and Infection 7(11):626-635.

Canton, R. (2009). Antibiotic Resistance Genes from the Environment: A Perspective through Newly identified Antibiotic Resistance Mechanisms in the Clinical Setting. European Society of Clinical Microbiology and Infectious Diseases 15(1):2025.

Ceylan, O., Okmen, G \& Ugur, A. (2008). Isolation of Soil Streptomyces as Sources Antibiotics Active against Antibiotic-resistant Bacteria. EurAsian Journal of BioSciences 2:73-82.

Cheesbrough, M. (2006). Direct Laboratory Practice in Tropical Countries, Vol.2. New York: Cambridge University Press.

Cummins, C.S. and Harris, H. (1956). The Chemical Composition of the Cell wall in some Grampositive Bacteria and its Possible Value as a Taxonomic Character. Journal of General microbiology 14(3):583-600.

Davies, J \& Davies, D. (2010). Origins and Evolution of Antibiotic Resistance. Molecular and Molecular Biology Reviews 74(3):417-433.

Dougherty, J.T \& Pucci, M.J. (2012). Antibiotic Discovery and Development. New York: Springer.

Harvey, R.A. (2007). Microbiology. Baltimore: Lippicncott Williams \& Wilkins.

Hopwood, D.A., Buttner, M.J., Kieser, T \& Charter, K.F. (2000). Antibiotic Production by Streptomyces. Practical Streptomyces Genetics 1:1-42. for more discovering of novel antimicrobial drugs and explorations. This solely depends on the results of research findings on antibiotics with much emphasis on actinomycetes.

thanks Dr. Kibera and Dr. Maingi for their academic advice.

Jeffery, L.S.H. (2011). Prescreening of Bioactivities from Actinomycetes Isolated from Forest Peat Soil of Sarawak. J. Trop. Agric. And Fd. 39(2):245-253.

Jeffrey, L.S.H. (2008). Isolation, Characterization and Identification of Actinomycetes from Agricultural Soils at Semongok, Sarawak. African Journal of Biotechnology 7(20):3697-3702.

Jorgensen, J.H \& Ferraro, M.J. (2009). Antimicrobial Susceptibility Testing: A Review of General Principles and Contemporary Practices. Clinical Infectious Diseases 49(11):1749-1755.

Kekuda T.R.P., Shobha, K.S \& Onkarappa, R. (2010). Fascinating Diversity and Potent Biological Activities of Actinomycete Metabolites. Journal of Pharmacy Research 3(2):250-256.

Kumar, S.K. (2001). Actinomycetes of an Indian Mangrove (Pichavaram) Environment: An Inventory. Ph.D. thesis, Annamalai University, India, $91 \mathrm{pp}$.

Oskay, M., Same, A., Azeri, C. (2004). Antibacterial Activity of some Actinomycetes Isolated from Farming Soils of Turkey. African Journal of Biotechnology 3(9): 441-446.

Pandey, A., Ali, I., butola, K.S., Chatterji, T \& Singh, V. (2011). Isolation and Characterization of Actinomycetes From Soil Evaluation of Antibacterial Activities of Actinomycetes Against Pathogens. International Journal of Applied Biology and Pharmaceutical Technology 2(4):384-392

Sacramenti, D.R., Coelho, R.R.R., Wigg, D.M., Linhares, L.T.F.L., Dos Santos, M.G.M., Semedo, L.T.A.S \& Silva, A.J.R. (2004). Antimicrobial and Antiviral Activities of an Actinomycete (Streptomyces sp.) Isolated from a Brazilian Tropical Forest Soil. World Journal of Microbiology and Biotechnology 20: 225-229.

Sumpradit, N., Chongtrakul, P., Anuwong, K., Pumtong, S., Kongsomboon., Butdeemee., Khonlormyati, 
Khasabuli and Kibera. J. Appl. Biosci. 2014. Screening of soil actinomycetes from Kenyatta university arboretum for antibacterial activities.

J., Chomyong, S., Tongyoung, P., Losiriwat, S., Seesuk, P., Suwanwaree, $P$ \& Tangcharoensathien, V. (2012). Antibiotics Smart Use: A Workable Model for Promoting the Rational Use of Medicines in Thailand. Bull World Health Organization 90:905-913.

Wheat, P.F. (2001). History and Development of Antimicrobial Susceptibility Testing Methodology. Journal of Antimicrobial Chemotherapy 48(1):1-4. 